\title{
Coexisting Chiral Two-Dimensional Self-Assembled Structures of 1,2,3,4-Tetrahydronaphthalene Molecules: Porous Pinwheel Nanoarchitecture and Close-Packed Herringbone Arrangement
}

\author{
Fabien Silly, ${ }^{* \dagger}$ (†) Sandrine Ausset, ${ }^{\dagger}$ and Xiaonan Sun ${ }^{*}$ \\ †TITANS, SPEC, CEA, CNRS, Université Paris-Saclay, CEA Saclay, F-91191 Gif sur Yvette, France \\ ‡Université Paris Diderot, Sorbonne Paris Cité, ITODYS UMR CNRS 7086, 15 rue J-A de Baif, 75205 Paris Cedex 13, France
}

ABSTRACT: The self-assembly of 1,2,3,4-tetrahydronaphthalene molecules is investigated using scanning tunneling microscopy (STM) at the solid/liquid interface. STM reveals that the molecule self-assembles into a chiral close-packed herringbone structure and a chiral porous pinwheel nanoarchitecture at room temperature on graphite. The two networks are equally distributed on the surface, and the two enantiomeric molecular arrangements of the two structures are observed. Variation of the molecule-surface epitaxial relation-
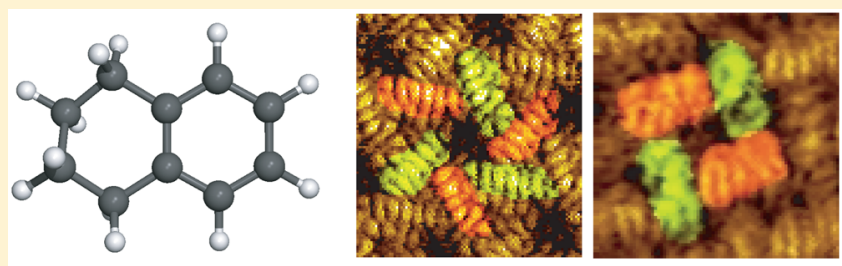

Chiral Two-Dimensional Self-Assembled Structures of 1,2,3,4-Tetrahydronaphthalene Molecules on Graphite ship suggests that the pinwheel arrangement favors moleculesurface interactions, whereas the herringbone arrangement favors intermolecular interactions.

\section{INTRODUCTION}

Molecular self-assembly is an appealing method to engineer nanoarchitectures and nanomaterials because this method offers unique directions for the fabrication of long-range structures with elementary organic nano-building-blocks. Highly selective and directional intermolecular interactions are usually employed to stabilize molecular arrangement into porous structures. Porous organic layers with tailored design have been successfully achieved taking advantage of intermolecular hydrogen-bonding, ${ }^{1-20}$ halogen-bonding, ${ }^{21-42}$ and hybrid metal-organic and organic-ionic interactions. ${ }^{43-46}$ In contrast with these interactions, van der Waals (vdW) interactions are weak and nondirectional interactions. These interactions are, however, omnipresent in self-assembled organic nanoarchitectures. ${ }^{47}$ Anticipating the structure of selfassembled organic nanoarchitectures is therefore not a straightforward task when molecular self-assemblies are expected to be exclusively driven by van der Waals interactions. Tahara et al., however, showed that porous $2 \mathrm{D}$ organic structures could be engineering by taking advantage of molecular alkyl chain interdigitation induced by van der Waals interactions. ${ }^{47,48}$ They also observed that molecules can in addition adopt chiral arrangements. This is of great technological interest as chiral nanoarchitectures have promising potentials for applications in nanotechnology. ${ }^{49}$ Chiral nanoarchitectures can emerge from molecular self-assembly. ${ }^{50,51} 2 \mathrm{D}$ chirality can result from the self-assembly of chiral building blocks ${ }^{52,53}$ and prochiral building blocks. ${ }^{54-56}$ In that case, the chirality of the molecule is transferred to the molecular assembly. ${ }^{57}$ Chiral structure can also be achieved using achiral molecules. ${ }^{1,54,55,58,59}$ In that case, the chirality results from the specific arrangement of the molecules. In the case of very small molecules made of few benzene rings, without alkyl chain and any specific substituant to drive intermolecular self-assembly, van der Waals interactions are expected to drive the formation of close-packed organic structures and the chirality of the resulting arrangements can hardly be predicted.

In this paper, we investigate experimentally the self-assembly of 1,2,3,4-tetrahydronaphthalene $\left(\mathrm{C}_{10} \mathrm{H}_{12}\right)$ on graphite at the solid liquid interface. Scanning tunneling microscopy (STM) reveals that the molecules self-assemble into a chiral porous nanoarchitecture and a chiral close-packed network at room temperature on graphite.

\section{EXPERIMENTAL SECTION}

A droplet of a 1,2,3,4-Tetrahydronaphthalene (T-naphthalene) solution (99\%, Sigma-Aldrich) is deposited on a freshly cleaved highly oriented pyrolytic graphite substrate. STM imaging of the samples is performed at the liquid-solid interface ${ }^{6-62}$ using a Pico-SPM scanning tunneling microscope (Molecular Imaging, Agilent Technology). Cut $\mathrm{Pt} / \mathrm{Ir}$ wires are used to obtain constant current images at room temperature with a bias voltage applied to the sample. STM images are processed and analyzed using the application FabViewer. ${ }^{63}$

\section{RESULTS}

The 1,2,3,4-tetrahydronaphthalene molecule (Figure 1) is the archetypal small molecule to investigate molecular self-assembly driven by van der Waals interactions. This small molecule is composed of a benzene ring attached to a cyclohexane ring.

Received: May 22, 2017

Revised: June 24, 2017

Published: June 26, 2017 


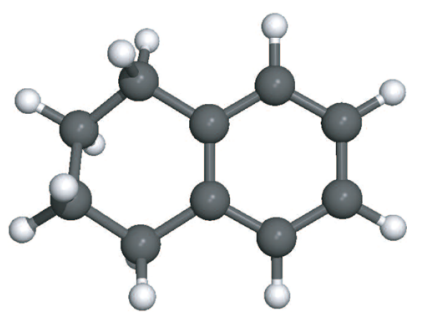

Figure 1. Scheme of the 1,2,3,4-tetrahydronaphthalene molecule $\left(\mathrm{C}_{10} \mathrm{H}_{12}\right)$. Carbon atoms are dark gray; hydrogen atoms are white.

The large-scale STM image in Figure 2 shows that molecules self-assemble into a porous nanoarchitecture on graphite at the

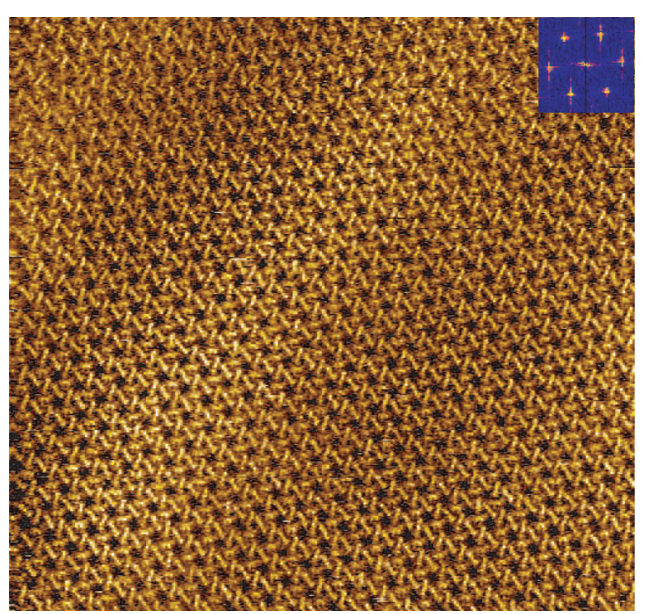

Figure 2. Large-scale STM image of the T-naphthalene porous network on graphite, $50 \times 47 \mathrm{~nm}^{2} ; V_{s}=+0.80 \mathrm{~V}, I_{t}=80 \mathrm{pA}$. Inset: Fast Fourier transform of the STM image.

solid-liquid interface. The fast Fourier transform of the STM image (inset) reveals that the molecular arrangement is hexagonal.

A high-resolution STM image of the organic hexagonal network is presented in Figure 3a. STM reveals that the molecular building block of this structure has a pinwheel shape (Figure $3 b$ ). It is composed of six molecules. The center of the pinwheel is empty. This nanoarchitecture is chiral. The two pinwheel enantiomers are presented in Figure $3 b, c$, respectively. The model of the 2D nanoarchitecture is presented in Figure $3 \mathrm{~d}$. The network unit cell of this structure is a lozenge with a $1.9 \mathrm{~nm}$ unit cell constant and an angle of $60^{\circ}$ between the axes. The lozenge unit cell is represented by dotted purple lines, and the pinwheel building block is surrounded by a blue dotted circle. The six molecules composing the molecular pinwheel are rotated by an angle of $60^{\circ}$ in comparison with their neighbors.

The large-scale STM image in Figure 4 shows that molecules also self-assemble into a close-packed nanoarchitecture on graphite at the solid-liquid interface. The fast Fourier transform of the STM image (inset) reveals that this molecular arrangement has a parallelogram unit cell.

The high-resolution STM image in Figure 5a shows that molecules adopt a herringbone arrangement in the closepacked domain. The network unit cell is a square with a $1.3 \mathrm{~nm}$ unit cell constant and an angle of $90^{\circ}$ between the axes. This unit cell contains four molecules. Neighboring molecules are rotated by an angle of $85^{\circ}$. The model of this close-packed structure is presented in Figure $5 \mathrm{~b}$. The square unit cell is
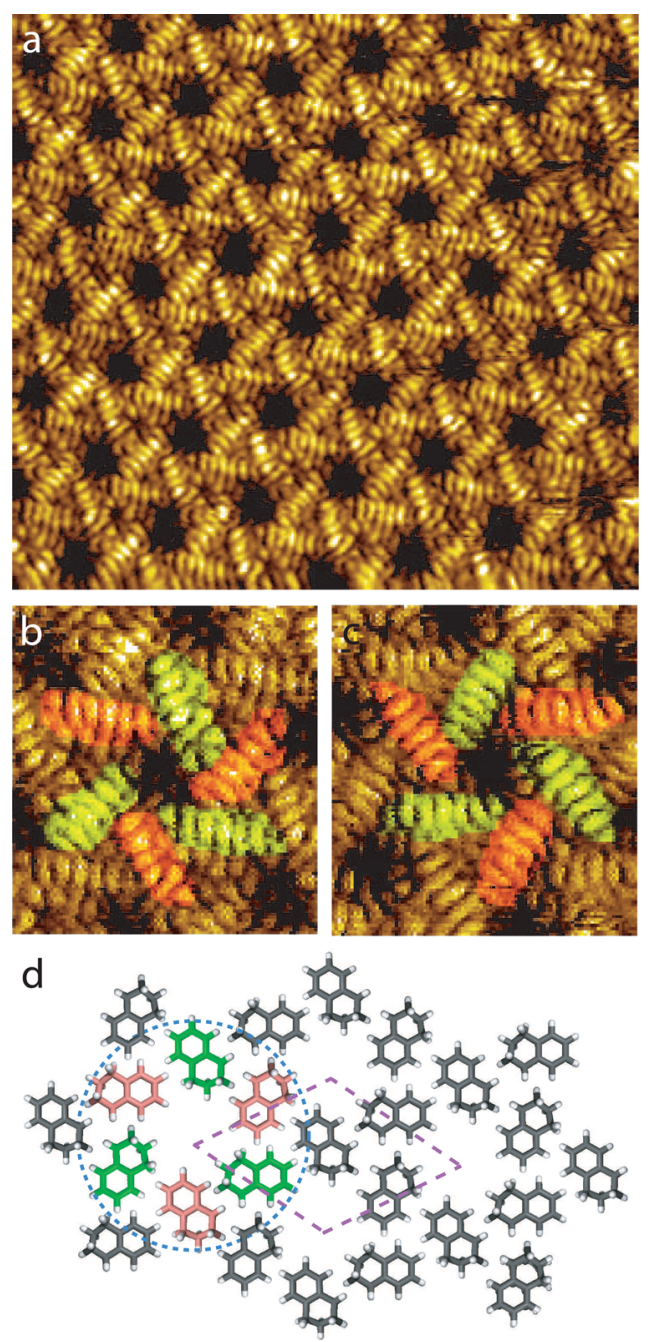

Figure 3. (a) STM image of the T-naphthalene pinwheel structure on graphite, $13 \times 12 \mathrm{~nm}^{2} ; V_{s}=0.19 \mathrm{~V}, I_{t}=0.3 \mathrm{nA}$. (b, c) STM images of the two pinwheel enantiomers, $4 \times 4 \mathrm{~nm}^{2} ; V_{s}=0.19 \mathrm{~V}, I_{t}=0.7 \mathrm{nA}$. The six molecules composing the pinwheel have been colored in red and green as a guide for the eyes. (d) Scheme of the unit cell. The unit cell is represented by dotted purple lines. One organic pinwheel is represented by red and green molecules to correspond to the STM image in (b). The pinwheel is surrounded by a dotted blue circle.

represented by dashed purple lines. This network is similar to the self-assembled herringbone structure of PTCDA molecules. $^{64}$

Figure 6 shows an STM image of the boundary between two herringbone domains. The two enantiomeric phases of the chiral herringbone arrangement can be observed in the same STM image. The four neighboring molecules forming the chiral network unit cell of each network have been colored in red and green as a guide for the eyes.

The chiral pinwheel and chiral herringbone nanoarchitectures are coexisting on the graphite surface. Figure 7 shows an STM image of the boundary between a herringbone and a pinwheel domain. The two dashed white rectangles superimposed to the STM image reveal that one molecule of the pinwheel network is aligned with one molecule of the herringbone structure. The different parameters of the pinwheel and herringbone nanoarchitectures are summarized in Table 1. Molecules can adopt different behavior at the domain boundary. ${ }^{65}$ In the case of 1,2,3,4-tetrahydronaphthalene 


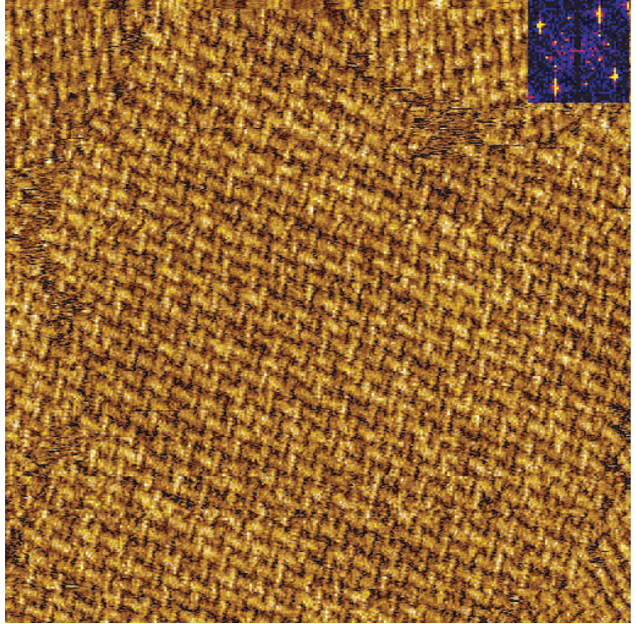

Figure 4. Large-scale STM image of the T-naphthalene compact network on graphite, $40 \times 40 \mathrm{~nm}^{2} ; V_{s}=+0.15 \mathrm{~V}, I_{t}=500$ pA. Inset: Fast Fourier transform of the STM image.
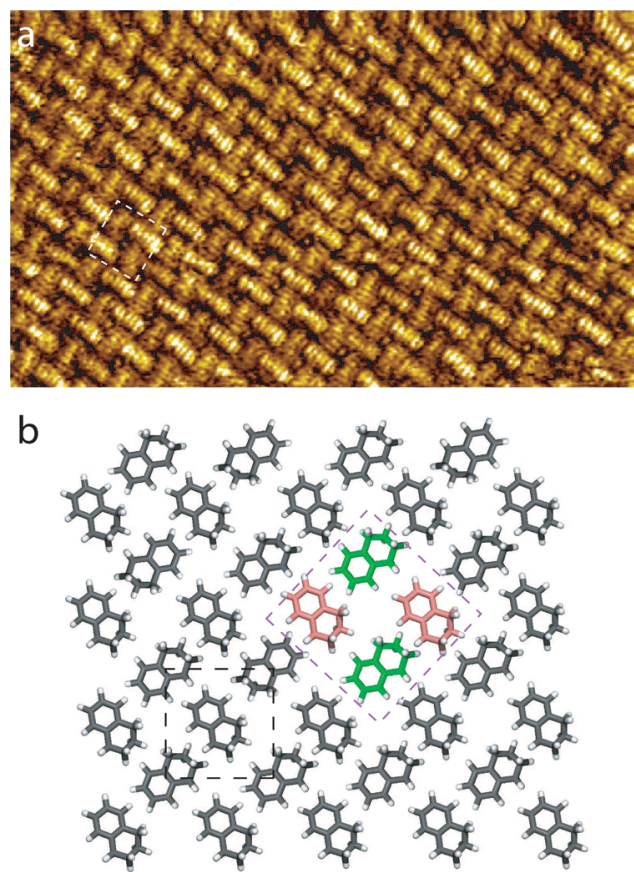

Figure 5. (a) STM image of the T-naphthalene herringbone structure on graphite, $22 \times 13 \mathrm{~nm}^{2} ; V_{s}=-0.3 \mathrm{~V}, I_{t}=0.2 \mathrm{nA}$. (b) Scheme of the compact herringbone nanoarchitecture. The unit cell is represented by a dashed black square. The four molecules composing the building block of this structure have been colored in green and red as a guide for the eyes. The building block is highlighted by a dashed purple square in (b) and a dashed white square in (a).

molecules, STM shows that the molecule can be mobile or can be fixed at the domain boundary.

\section{DISCUSSION}

The STM images are showing that T-naphthalene selfassembles into two chiral nanoarchitectures on graphite at the solid-liquid interface. T-naphthalene $\left(\mathrm{C}_{10} \mathrm{H}_{12}\right)$ and naphthalene $\left(\mathrm{C}_{10} \mathrm{H}_{8}\right)$ have very similar skeletons; i.e., the two molecular skeletons are composed of two hexagonal carbon rings. The self-assembly of naphthalene on metal surfaces has been investigated in the past. Naphthalene molecules deposited on

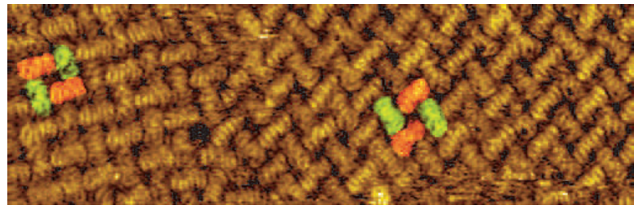

Figure 6. STM image of the domain boundary between two enantiomeric T-naphthalene close-packed structures on graphite, 21 $\times 7 \mathrm{~nm}^{2} ; V_{s}=-0.40 \mathrm{~V}, I_{t}=0.2 \mathrm{nA}$. The four molecules composing the herringbone structure for the two enantiomeric domains have been colored in red and green as a guide for the eyes.

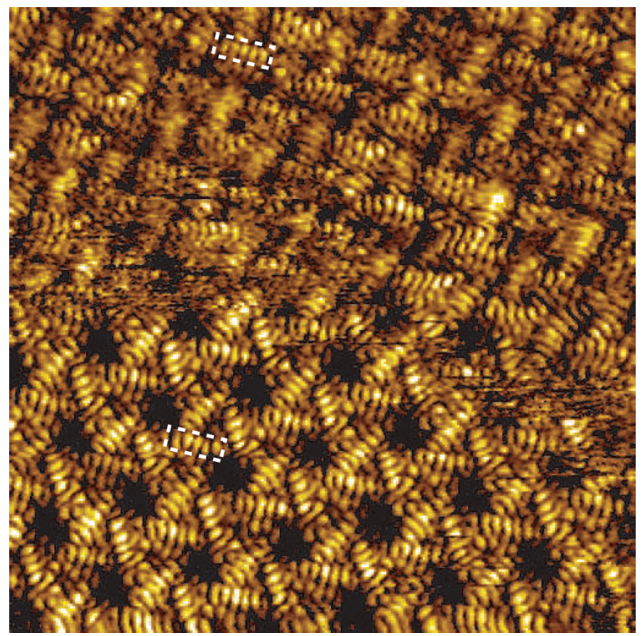

Figure 7. STM image of the domain boundary between the herringbone and pinwheel domains, $13 \times 13 \mathrm{~nm}^{2} ; V_{s}=-0.19 \mathrm{~V}, I_{t}$ $=0.5 \mathrm{nA}$.

Table 1. Lengths (in $\AA$ ) of the Two Lattice Vectors $\left(A_{1}\right.$ and $A_{2}$ ) and the Angle $\theta$ between Them (in Degrees) for the Two T-naphthalene Nanoarchitectures ${ }^{a}$

\begin{tabular}{lll} 
2D structure & \multicolumn{1}{c}{ pinwheel } & herringbone \\
$A_{1}$ & 1.9 & 1.3 \\
$A_{2}$ & 1.9 & 1.3 \\
$\theta$ & $60^{\circ}$ & $90^{\circ}$ \\
$\tau$ & $60^{\circ}$ & $85^{\circ}$ \\
mol/unit cell & 3 & 2 \\
density & $0.96 \mathrm{~mol} / \mathrm{nm}^{2}$ & $1.18 \mathrm{~mol} / \mathrm{nm}^{2}$
\end{tabular}

${ }^{a}$ The difference in the orientations of the two molecules within the cell is shown by the angle $\tau$ (also in degrees).

$\mathrm{Cu}(111)$ were previously observed to form a chiral structure as well as a nonchiral rectangular and a lozenge structure, where molecules are aligned in the same direction. ${ }^{66,67}$ The aligned naphthalene structure was also observed on $\mathrm{Rh}(111){ }^{68}$ This arrangement was coexisting with a close-packed structure, where the angle between molecules is $60^{\circ} .{ }^{69}$ The $T$ naphthalene structures presented in Figures 3 and 5 differ from naphthalene 2D nanoarchitectures. Due to the chemical nature of the naphthalene substituents ( $\mathrm{H}$ atoms), the pinwheel and the herringbone nanoarchitectures appear to be stabilized by van der Waals interactions.

The pinwheel structure and the herringbone arrangement are surprisingly covering equally the graphite surface; i.e., none of the arrangements appear to be favored. The intermolecular interaction energy of the herringbone arrangement is expected to be smaller than the one of the pinwheel structure because 
the close-packed arrangement and higher density of the herringbone structure (Table 1) are expected to maximize van der Waals interactions between neighboring molecules. The adsorption energy of the pinwheel nanoarchitecture should in contrast be lower than the one of the herringbone arrangement. The pinwheel arrangement possesses a 6-symmetry axis, like the graphite surface. This means that the epitaxial relationship of the molecule with the surface is optimized. This is not the case for the herringbone structure, which has a 4-fold symmetry. Figure 7 shows that only one molecule of the herringbone structure is adopting the same orientation as the molecules in the pinwheel structure. The experimental observations therefore reveal that the subtle balance between intermolecular interactions and molecule-surface interactions is not privileging the pinwheel structure or the herringbone arrangement on graphite; i.e., the molecule-surface interaction appears to be minimized in the pinwheel structure, whereas intermolecular interaction is minimized in the herringbone arrangement. One way to privilege the growth of one of the networks would be to change the supporting surface to tune the molecule-surface interaction. ${ }^{70,71}$

\section{CONCLUSION}

To summarize, T-naphthalene molecules self-assemble into a chiral close-packed squared herringbone arrangement and chiral hexagonal pinwheel nanoarchitectures on graphite at the solidliquid interface. The two structures appear to be both stabilized by van der Waals interactions. The two structures are coexisting on the surface; the enantiomeric domains of the two chiral arrangements have been observed. None of the self-assembled structures appear to be privileged; i.e., intermolecular interactions and molecule-surface interactions are not favoring one of the two $2 \mathrm{D}$ arrangements.

\section{AUTHOR INFORMATION}

\section{Corresponding Author}

*E-mail: fabien.silly@cea.fr. Phone: +33(0)169088019. Fax: $+33(0) 169088446$.

\section{ORCID}

Fabien Silly: 0000-0001-6782-9268

\section{Notes}

The authors declare no competing financial interest.

\section{ACKNOWLEDGMENTS}

The research leading to these results has received funding from the European Research Council under the European Union's Seventh Framework Programme (FP7/2007-2013)/ERC grant agreement no. 259297.

\section{REFERENCES}

(1) Pawin, G.; Wong, K. L.; Kwon, K.-Y.; Bartels, L. A Homomolecular Porous Network at a $\mathrm{Cu}(111)$ Surface. Science 2006, 313, 961-962.

(2) Yan, H.-J.; Liu, J.; Wang, D.; Wan, L.-J. Two-Dimensional SelfAssemblies of Telechelic Organic Compounds: Structure and Surface Host-Guest Chemistry. Philos. Trans. R. Soc., A 2013, 371, 20120302.

(3) Uemura, S.; Aono, M.; Komatsu, T.; Kunitake, M. TwoDimensional Self-Assembled Structures of Melamine and Melem at the Aqueous Solution-Au(111) Interface. Langmuir 2011, 27, 13361340.

(4) Shen, C.; Cebula, I.; Brown, C.; Zhao, J.; Zharnikov, M.; Buck, M. Structure of Isophthalic Acid Based Monolayers and its Relation to the
Initial Stages of Growth of Metal-Organic Coordination Layers. Chem. Sci. 2012, 3, 1858-1865.

(5) Temirov, R.; Soubatch, S.; Neucheva, O.; Lassise, A. C.; Tautz, F. S. A Novel Method Achieving Ultra-High Geometrical Resolution in Scanning Tunnelling Microscopy. New J. Phys. 2008, 10, 053012.

(6) Chen, T.; Yang, W.-H.; Wang, D.; Wan, L.-J. Globally Homochiral Assembly of Two-Dimensional Molecular Networks Triggered by Co-Absorbers. Nat. Commun. 2013, 4, 1389.

(7) Liang, H.; Sun, W.; Jin, X.; Li, H.; Li, J.; Hu, X.; Teo, B. K.; Wu, K. Two-Dimensional Molecular Porous Networks Formed by Trimesic Acid and 4,4'Bis(4-pyridyl)biphenyl on $\mathrm{Au}(111)$ through Hierarchical Hydrogen Bonds: Structural Systematics and Control of Nanopore Size and Shape. Angew. Chem., Int. Ed. 2011, 50, 75627566.

(8) Silly, F.; Shaw, A. Q.; Briggs, G. A. D.; Castell, M. R. Epitaxial Ordering of a Perylenetetracarboxylic Diimide-melamine Supramolecular Network Driven by the $\mathrm{Au}(111)-(22 \times \sqrt{3})$ Reconstruction. Appl. Phys. Lett. 2008, 92, 023102.

(9) Gardener, J. A.; Shvarova, O. Y.; Briggs, G. A. D.; Castell, M. R. Intricate Hydrogen-Bonded Networks: Binary and Ternary Combinations of Uracil, PTCDI, and Melamine. J. Phys. Chem. C 2010, 114, 5859-5866.

(10) Yagai, S. Supramolecularly Engineered Functional $\pi$-Assemblies Based on Complementary Hydrogen-Bonding Interactions. Bull. Chem. Soc. Jpn. 2015, 88, 28-58.

(11) Xu, L.; Miao, X.; Zha, B.; Deng, W. Hydrogen-Bonding-Induced Polymorphous Phase Transitions in 2D Organic Nanostructures. Chem. - Asian J. 2013, 8, 926-933.

(12) Tanioku, C.; Matsukawa, K.; Matsumoto, A. Thermochromism and Structural Change in Polydiacetylenes Including Carboxy and 4Carboxyphenyl Groups as the Intermolecular Hydrogen Bond Linkages in the Side Chain. ACS Appl. Mater. Interfaces 2013, 5, 940-948.

(13) Hu, Y.; Miao, K.; Zha, B.; Xu, L.; Miao, X.; Deng, W. STM Investigation of Structural Isomers: Alkyl Chain Position Induced SelfAssembly at the Liquid/Solid Interface. Phys. Chem. Chem. Phys. 2016, $18,624-634$.

(14) Priimagi, A.; Lindfors, K.; Kaivola, M.; Rochon, P. Efficient Surface-Relief Gratings in Hydrogen-Bonded Polymer-Azobenzene Complexes. ACS Appl. Mater. Interfaces 2009, 1, 1183-1189.

(15) Hieulle, J.; Silly, F. Localized Intermolecular Electronic Coupling in Two-Dimensional Self-Assembled 3,4,9,10-perylenetetracarboxylic Diimide Nanoarchitectures. J. Mater. Chem. C 2013, 1, $4536-4539$.

(16) Hu, Y.; Miao, K.; Peng, S.; Zha, B.; Xu, L.; Miao, X.; Deng, W. Structural Transition Control Between Dipole-Dipole and Hydrogen Bonds Induced Chirality and Achirality. CrystEngComm 2016, 18, 3019-3032.

(17) Barth, J. V. Molecular Architectonic on Metal Surfaces. Annu. Rev. Phys. Chem. 2007, 58, 375-407.

(18) Silly, F. Two-Dimensional 1,3,5-Tris(4-carboxyphenyl)benzene Self-Assembly at the 1-Phenyloctane/Graphite Interface Revisited. J. Phys. Chem. C 2012, 116, 10029-10032.

(19) Sun, X.; Jonkman, H. T.; Silly, F. Tailoring Two-Dimensional PTCDA-melamine Self-Assembled Architectures at Room Temperature by Tuning Molecular Ratio. Nanotechnology 2010, 21, 165602.

(20) Räisänen, M. T.; Slater, A. G.; Champness, N. R.; Buck, M. Effects of Pore Modification on the Templating of Guest Molecules in a 2D Honeycomb Network. Chem. Sci. 2012, 3, 84-92.

(21) Shen, Q.; He, J. H.; Zhang, J. L.; Wu, K.; Xu, G. Q.; Wee, A. T. S.; Chen, W. Self-Assembled Two-Dimensional Nanoporous Molecular Arrays and Photoinduced Polymerization of 4-bromo-4hydroxybiphenyl on $\operatorname{Ag}(111)$. J. Chem. Phys. 2015, 142, 101902.

(22) Xu, J.; Liu, X.; Ng, J. K.-P.; Lin, T.; He, C. Trimeric Supramolecular Liquid Crystals Induced by Halogen Bonds. J. Mater. Chem. 2006, 16, 3540-3545.

(23) Gao, H. Y.; Shen, Q. J.; Zhao, X. R.; Yan, X. Q.; Pang, X.; Jin, W. J. Phosphorescent Co-Crystal Assembled by 1,4-diiodotetrafluoroben- 
zene with Carbazole Based on C-I $\cdots \pi$ Halogen Bonding. J. Mater. Chem. 2012, 22, 5336-5343.

(24) Peyrot, D.; Silly, F. On-Surface Synthesis of Two-Dimensional Covalent Organic Structures versus Halogen-Bonded Self-Assembly: Competing Formation of Organic Nanoarchitectures. ACS Nano 2016, $10,5490-5498$.

(25) Getmanenko, Y. A.; Fonari, M.; Risko, C.; Sandhu, B.; Galán, E.; Zhu, L.; Tongwa, P.; Hwang, D. K.; Singh, S.; Wang, H.; et al. Benzo[1,2-b:6,5- $\left.\mathrm{b}^{\prime}\right]$ dithiophene(dithiazole)-4,5-dione Derivatives: Synthesis, Electronic Properties, Crystal Packing and Charge Transport. J. Mater. Chem. C 2013, 1, 1467-1481.

(26) Lafferentz, L.; Eberhardt, V.; Dri, C.; Africh, C.; Comelli, G.; Esch, F.; Hecht, S.; Grill, L. Controlling On-Surface Polymerization by Hierarchical and Substrate-Directed Growth. Nat. Chem. 2012, 4, 215-220.

(27) Shang, J.; Wang, Y.; Chen, M.; Dai, J.; Zhou, X.; Kuttner, J.; Hilt, G.; Shao, X.; Gottfried, J. M.; Wu, K. Assembling Molecular Sierpiński Triangle Fractals. Nat. Chem. 2015, 7, 389-393.

(28) Silly, F. Selecting Two-Dimensional Halogen-Halogen Bonded Self-Assembled 1,3,5-Tris(4-iodophenyl)benzene Porous Nanoarchitectures at the Solid-Liquid Interface. J. Phys. Chem. C 2013, 117, 20244-20249.

(29) Getmanenko, Y. A.; Fonari, M.; Risko, C.; Sandhu, B.; Galán, E.; Zhu, L.; Tongwa, P.; Hwang, D. K.; Singh, S.; Wang, H.; et al. Benzo[1,2-b:6,5-b]dithiophene(dithiazole)-4,5-dione derivatives: synthesis, electronic properties, crystal packing and charge transport. $J$. Mater. Chem. C 2013, 1, 1467-1481.

(30) Metrangolo, P.; Resnati, G.; Pilati, T.; Liantonio, R.; Meyer, F. Engineering Functional Materials by Halogen Bonding. J. Polym. Sci, Part A: Polym. Chem. 2007, 45, 1-15.

(31) Meyer, F.; Dubois, P. Halogen Bonding at Work: Recent Applications in Synthetic Chemistry and Materials Science. CrystEngComm 2013, 15, 3058-3071.

(32) Voth, A. R.; Khuu, P.; Oishi, K.; Ho, P. S. Halogen Bonds as Orthogonal Molecular Interactions to Hydrogen Bonds. Nat. Chem. 2009, 1, 74-79.

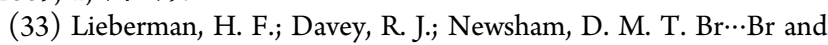
$\mathrm{Br} \cdots \mathrm{H}$ Interactions in Action: Polymorphism, Hopping, and Twinning in 1,2,4,5-Tetrabromobenzene. Chem. Mater. 2000, 12, 490-494.

(34) Gutzler, R.; Fu, C.; Dadvand, A.; Hua, Y.; MacLeod, J. M.; Rosei, F.; Perepichka, D. F. Halogen Bonds in 2D Supramolecular SelfAssembly of Organic Semiconductors. Nanoscale 2012, 4, 5965-5971.

(35) DiLullo, A.; Chang, S.-H.; Baadji, N.; Clark, K.; Klöckner, J.-P.; Prosenc, M.-H.; Sanvito, S.; Wiesendanger, R.; Hoffmann, G.; Hla, S.W. Molecular Kondo Chain. Nano Lett. 2012, 12, 3174-3179.

(36) Chung, K.-H.; Kim, H.; Jang, W. J.; Yoon, J. K.; Kahng, S.-J.; Lee, J.; Han, S. Molecular Multistate Systems Formed in TwoDimensional Porous Networks on $\mathrm{Ag}(111)$. J. Phys. Chem. C 2013, 117, 302-306.

(37) Baris, B.; Luzet, V.; Duverger, E.; Sonnet, P.; Palmino, F.; Chérioux, F. Robust and Open Tailored Supramolecular Networks Controlled by the Template Effect of a Silicon Surface. Angew. Chem., Int. Ed. 2011, 50, 4094-4098.

(38) Meazza, L.; Foster, J. A.; Fucke, K.; Metrangolo, P.; Resnati, G.; Steed, J. W. Halogen-Bonding-Triggered Supramolecular Gel Formation. Nat. Chem. 2013, 5, 42-47.

(39) Sun, A.; Lauher, J. W.; Goroff, N. S. Preparation of Poly(diiododiacetylene), an Ordered Conjugated Polymer of Carbon and Iodine. Science 2006, 312, 1030-1034.

(40) Pigge, F. C.; Vangala, V. R.; Kapadia, P. P.; Swenson, D. C.; Rath, N. P. Hexagonal Crystalline Inclusion Complexes of 4iodophenoxy Trimesoate. Chem. Commun. 2008, 4726-4728.

(41) Metrangolo, P.; Meyer, F.; Pilati, T.; Resnati, G.; Terraneo, G. Mutual induced coordination in halogen-bonded anionic assemblies with $(6,3)$ cation-templated topologies. Chem. Commun. 2008, 16351637.

(42) Zha, B.; Dong, M.; Miao, X.; Peng, S.; Wu, Y.; Miao, K.; Hu, Y.; Deng, W. Cooperation and competition between halogen bonding and van der Waals forces in supramolecular engineering at the aliphatic hydrocarbon/graphite interface: position and number of bromine group effects. Nanoscale 2017, 9, 237-250.

(43) Urgel, J. I.; Écija, D.; Lyu, G.; Zhang, R.; Palma, C.-A.; Auwärter, W.; Lin, N.; Barth, J. V. Quasicrystallinity Expressed in TwoDimensional Coordination Networks. Nat. Chem. 2016, 8, 657-662.

(44) Zhang, C.; Wang, L.; Xie, L.; Ding, Y.; Xu, W. On-Surface DualResponse Structural Transformations of Guanine Molecules and $\mathrm{Fe}$ Atoms. Chem. - Eur. J. 2017, 23, 2356-2362.

(45) Sun, Q.; Cai, L.; Ma, H.; Yuan, C.; Xu, W. On-Surface Construction of a Metal-Organic Sierpiński Triangle. Chem. Commun. 2015, 51, 14164-14166.

(46) Cirera, B.; Đorđević, L.; Otero, R.; Gallego, J. M.; Bonifazi, D.; Miranda, R.; Ecija, D. Dysprosium-Carboxylate Nanomeshes with Tunable Cavity Size and Assembly Motif Through Ionic Interactions. Chem. Commun. 2016, 52, 11227-11230.

(47) Tahara, K.; Lei, S.; Adisoejoso, J.; De Feyter, S.; Tobe, Y. Supramolecular Surface-Confined Architectures Created by SelfAssembly of Triangular Phenylene-Ethynylene Macrocycles via van der Waals Interaction. Chem. Commun. 2010, 46, 8507-8525.

(48) Tahara, K.; Yamaga, H.; Ghijsens, E.; Inukai, K.; Adisoejoso, J.; Blunt, M. O.; De Feyter, S.; Tobe, Y. Control and Induction of Surface-Confined Homochiral Porous Molecular Networks. Nat. Chem. 2011, 3, 714-719.

(49) Yagai, S.; Yamauchi, M.; Kobayashi, A.; Karatsu, T.; Kitamura, A.; Ohba, T.; Kikkawa, Y. Control over Hierarchy Levels in the SelfAssembly of Stackable Nanotoroids. J. Am. Chem. Soc. 2012, 134, 18205-18208.

(50) Ernst, K.-H. Molecular Chirality in Surface Science. Surf. Sci. 2013, 613, 1-5.

(51) Chen, T.; Wang, D.; Wan, L.-J. Two-dimensional Chiral molecular Assembly on Solid Surfaces: Formation and Regulation. Nat. Sci. Rev. 2015, 2, 205-216.

(52) Haq, S.; Liu, N.; Humblot, V.; Jansen, A. P. J.; Raval, R. Drastic Symmetry Breaking in Supramolecular Organization of Enantiomerically Unbalanced Monolayers at Surfaces. Nat. Chem. 2009, 1, 409414.

(53) Fasel, R.; Parschau, M.; Ernst, K.-H. Amplification of Chirality in Two-Dimensional Enantiomorphous Lattices. Nature 2006, 439, 449452.

(54) De Cat, I.; Guo, Z.; George, S. J.; Meijer, E. W.; Schenning, A. P. H. J.; De Feyter, S. Induction of Chirality in an Achiral Monolayer at the Liquid/Solid Interface by a Supramolecular Chiral Auxiliary. J. Am. Chem. Soc. 2012, 134, 3171-3177.

(55) Prins, L. J.; De Jong, F.; Timmerman, P.; Reinhoudt, D. N. An Enantiomerically Pure Hydrogen-Bonded Assembly. Nature 2000, 408, 181-184.

(56) Lu, C.; Wei, Y.; Zhu, E.; Reutt-Robey, J. E.; Xu, B. Polymorphism in Self-Assembled Structures of 9-Anthracene Carboxylic Acid on $\mathrm{Ag}(111)$. Int. J. Mol. Sci. 2012, 13, 6836-6848.

(57) Fasel, R.; Parschau, M.; Ernst, K. Chirality Transfer from Single Molecules into Self-Assembled Monolayers. Angew. Chem., Int. Ed. 2003, 42, 5178-5181.

(58) Klappenberger, F.; Kühne, D.; Krenner, W.; Silanes, I.; Arnau, A.; García de Abajo, F. J.; Klyatskaya, S.; Ruben, M.; Barth, J. V. Dichotomous Array of Chiral Quantum Corrals by a Self-Assembled Nanoporous Kagomé Network. Nano Lett. 2009, 9, 3509-3514.

(59) Écija, D.; Seufert, K.; Heim, D.; Auwärter, W.; Aurisicchio, C.; Fabbro, C.; Bonifazi, D.; Barth, J. V. Hierarchic Self-Assembly of Nanoporous Chiral Networks with Conformationally Flexible Porphyrins. ACS Nano 2010, 4, 4936-4942.

(60) Maeda, H.; Shirai, T.; Uemura, S. Anion-Driven Structures of Radially Arranged Anion Receptor Oligomers. Chem. Commun. 2013, $49,5310-5312$.

(61) Miao, X.; Xu, L.; Li, Y.; Li, Z.; Zhou, J.; Deng, W. Tuning the Packing Density of Host Molecular Self-ssemblies at the Solid-Liquid Interface Using Guest Molecule. Chem. Commun. 2009, 46, 8830.

(62) Elemans, J. A. A. W.; Wezenberg, S. J.; Coenen, M. J. J.; Escudero-Adán, E. C.; Benet-Buchholz, J.; den Boer, D.; Speller, S.; Kleij, A. W.; De Feyter, S. Axial Ligand Control over Monolayer and 
Bilayer Formation of Metal-Salophens at the Liquid-Solid Interface. Chem. Commun. 2010, 46, 2548.

(63) Silly, F. A Robust Method For Processing Scanning Probe Microscopy Images and Determining Nanoobject Position and Dimensions. J. Microsc. 2009, 236, 211-218.

(64) Mura, M.; Sun, X.; Silly, F.; Jonkman, H. T.; Briggs, G. A. D.; Castell, M. R.; Kantorovich, L. N. Experimental and Theoretical Analysis of H-Bonded Supramolecular Assemblies of PTCDA Molecules. Phys. Rev. B: Condens. Matter Mater. Phys. 2010, 81, 195412.

(65) Silly, F. Two-Dimensional Self-Assembly of 2,4,6-Tris(4,4,4Trimethylphenyl)-1,3,5-Triazine Star-Shaped Molecules: Nanoarchitecture Structure and Domain Boundaries. J. Phys. Chem. C 2014, 118, 11975-11979.

(66) Yamada, T.; Shibuta, M.; Ami, Y.; Takano, Y.; Nonaka, A.; Miyakubo, K.; Munakata, T. Novel Growth of Naphthalene Overlayer on $\mathrm{Cu}(111)$ Studied by STM, LEED, and 2PPE. J. Phys. Chem. C 2010, 114, 13334-13339.

(67) Wan, L.; Itaya, K. In Situ Scanning Tunneling Microscopy of Benzene, Naphthalene, and Anthracene Adsorbed on $\mathrm{Cu}(111)$ in Solution. Langmuir 1997, 13, 7173-7179.

(68) Inukai, J.; Wakisaka, M.; Itaya, K. Adlayer of Naphthalene on $\mathrm{Rh}$ (111) Studied by Scanning Tunneling Microscopy. Jpn. J. Appl. Phys. 2004, 43, 4554-4556.

(69) Yau, S.-L.; Kim, Y.-G.; Itaya, K. High-Resolution Imaging of Aromatic Molecules Adsorbed on $\mathrm{Rh}(111)$ and $\mathrm{Pt}(111)$ in Hydrofluoric Acid Solution: In Situ STM Study. J. Phys. Chem. B 1997, 101, 3547-3553.

(70) Deak, D. S.; Silly, F.; Porfyrakis, K.; Castell, M. R. Template ordered open-grid arrays of paired endohedral fullerenes. J. Am. Chem. Soc. 2006, 128, 13976-13977.

(71) Deak, D. S.; Silly, F.; Porfyrakis, K.; Castell, M. R. Controlled surface ordering of endohedral fullerenes with a $\mathrm{SrTiO}_{3}$ template. Nanotechnology 2007, 18, 075301. 